\title{
A study of morphological properties of $\mathrm{SiO}_{2}$ aerogels obtained at different temperatures
}

\author{
Jin-jun LIAO ${ }^{a}$, Peng-zhao GAO ${ }^{a,}{ }^{*}$, Lin $\mathrm{XU}^{b}$, Jian $\mathrm{FENG}^{b}$ \\ ${ }^{a}$ College of Materials Science and Engineering, Hunan University, Changsha 410082, China \\ ${ }^{b}$ Key Laboratory of New Ceramic Fibers and Composites, National University of \\ Defense Technology, Changsha 410082, China
}

Received: March 3, 2018; Revised: May 2, 2018; Accepted: May 2, 2018

(C) The Author(s) 2018. This article is published with open access at Springerlink.com

\begin{abstract}
In this paper, temperature dependence of nanoporous framework evolution process and variety of pore properties (pore volume, specific surface area (BET), and pore size) of $\mathrm{SiO}_{2}$ aerogels were characterized by FTIR, XPS, XRD, SEM, TEM, BET, BJH, etc. Results show that $\mathrm{SiO}_{2}$ aerogels treated at different temperatures all possess amorphous structure. With the increase of treated temperatures, BET values of $\mathrm{SiO}_{2}$ aerogels increase initially and then decrease, and it reaches the maximum value of $882.81 \mathrm{~m}^{2} / \mathrm{g}$ when treated at $600{ }^{\circ} \mathrm{C}$ for $2 \mathrm{~h}$ due to the addition of the nanopores and shrinkage skeleton of $\mathrm{SiO}_{2}$ aerogels. Higher temperatures may result in a framework transformation and particle growth; both factors could reduce the BET values of the aerogels. Nanoporous skeleton of $\mathrm{SiO}_{2}$ aerogels at room temperatures is composed of tetrahedron with a pore size of about $22.28 \mathrm{~nm}$. Higher treated temperatures result in an increase of octahedron amount in nanoporous framework and a decrease of pore size. When treated at $1000{ }^{\circ} \mathrm{C}$, an approximate dense $\mathrm{SiO}_{2}$ bulk via the framework collapse and particle growth is obtained. These varieties are derived from the formed extra bonds of $\mathrm{Si}-\mathrm{O}-\mathrm{Si}$, higher local stress, and liquid phase between particles during heat treatment process.
\end{abstract}

Keywords: silica aerogel; temperature dependence; nanoporous framework evolution; pore properties

\section{Introduction}

Silica $\left(\mathrm{SiO}_{2}\right)$ aerogels show potential applications in the fields of catalysis, environmental protection, thermal insulation materials, electrical, optics, acoustic impedance materials, low bulk density materials $\left(\sim 0.03 \mathrm{~g} / \mathrm{cm}^{3}\right)$, nanoporous materials, high porosity $(>90 \%)$, high surface area $\left(500-1000 \mathrm{~m}^{2} / \mathrm{g}\right)$ and low thermal conductivity $(0.005 \mathrm{~W} /(\mathrm{m} \cdot \mathrm{K}))$ materials [1-5], due to

* Corresponding author.

E-mail: gaopengzhao7602@hnu.edu.cn the nanoparticles and special nanoporous framework. While the special skeleton of aerogel may be destroyed and nanoparticles may grow up at higher temperatures, both can acutely reduce the density and thermal properties of $\mathrm{SiO}_{2}$ aerogel [6]. Many researches concentrated on strengthening the thermal stability and strength of the aerogel via the preparation of hybrid aerogels [7-11]. Kim et al. [9] synthesized a glass fiber/silica aerogel, which possessed bigger pore size and specific surface area than aerogel composites made of only colloidal silica. Wu et al. [10] fabricated aerogel composites using a multilayer aligned glass 
fiber as reinforcer, which owned a low thermal conductivity of $0.022-0.028 \mathrm{~W} /(\mathrm{m} \cdot \mathrm{K})$ and compressive strength of 1.71-3.70 MPa. Fenech et al. [11] prepared $\mathrm{ZrO}_{2} / \mathrm{Y}_{2} \mathrm{O}_{3}$ aerogels with BET surface area of 159 and $26 \mathrm{~m}^{2} / \mathrm{g}$ after heat treatment at 550 and $1000{ }^{\circ} \mathrm{C}$ respectively.

It is known that the performance of a porous material depends on the pore size and framework structure [12], and these will vary at high temperatures. There are a limited number of studies that report the relationship between the nanoporous framework formation and particle growth process with the pore properties of $\mathrm{SiO}_{2}$ aerogels obtained at different temperatures [16]. Zhou et al. [13] studied the framework structure of aerogels with two different granular sizes of 5 and 20 $\mathrm{nm}$. They found that the small pores collapsed while the large pores expended after calcination at high temperatures. Huang et al. investigated the structural changes of silica aerogels in the $950-1200{ }^{\circ} \mathrm{C}$ temperature range. Their results showed that the process consists of three steps $[14,15]$.

The aim of this work is to study the process of $\mathrm{SiO}_{2}$ aerogel nanoporous framework formation and particle growth at different temperatures with a series of physicochemical methods, among others with FTIR, XPS, and TEM, to propose a qualitative regular polyhedron model of the process.

\section{Experimental}

\section{1 Synthesis}

The synthesis of silica aerogels involves two steps: (i) the preparation of an alcogel and (ii) the solvent removal from the alcogel by ethanol supercritical drying [17]. The alcogel was prepared from tetraethoxysilane (TEOS) by a two-step method. Firstly, the designed amount of TEOS was dissolved in alcohol and then the mixture was stirred for $30 \mathrm{~min}$ at $35{ }^{\circ} \mathrm{C}$. Then, the designed amounts of water, alcohol, and catalyst were mixed and the mixture obtained was added dropwise to the TEOS solution under continuous stirring. In order to obtain alcogel with a stable structure, alcogel was submerged under alcohol for two days at room temperature. Finally, the alcogel was heated at a rate of $1{ }^{\circ} \mathrm{C} / \mathrm{min}$ to $300{ }^{\circ} \mathrm{C}$. When the temperature reached $300{ }^{\circ} \mathrm{C}$, the pressure was kept at $10 \mathrm{MPa}$ for $2 \mathrm{~h}$. This step was followed with a controlled cooling step to produce the aerogel [18].
The aerogels obtained were calcined under air atmosphere at different temperatures $(400,600,700$, 800 , and $1000{ }^{\circ} \mathrm{C}$ ) to study the process of the nanoporous framework evolution, with a heating rate of $10{ }^{\circ} \mathrm{C} / \mathrm{min}$. The holding time was designed as 2,4 , and $8 \mathrm{~h}$.

\section{2 Characterization}

The phase composition of the aerogels was analyzed by powder X-ray diffraction using a D5000 apparatus (Siemens). The scanning rate was $2\left(^{\circ}\right) /$ min using nickel filtered $\mathrm{Cu} \mathrm{K \alpha}$ radiation produced at $30 \mathrm{kV}$ and $30 \mathrm{~mA}$. The oxidation state was investigated by X-ray photoelectron spectroscopy (XPS) using a Kratos AXIS Ultra spectrometer, equipped with a monochromatic $\mathrm{Al}$ $\mathrm{K} \alpha \mathrm{X}$-ray source, a delay-line detector, and an $\mathrm{Al}$ anode (Al K $\alpha=1486.71 \mathrm{eV}$ ) operated at $225 \mathrm{~W}$. The XPS spectra collected were analyzed using an XPSpeak software and calibrated using the adventitious $\mathrm{O} 1 \mathrm{~s}$ peak with a fixed value of $533.3 \mathrm{eV}$. A Shirley-type background subtraction was used to fit the curve using a $20 \%$ Gaussian- $80 \%$ Lorentzian function. The framework structure of the aerogels was characterized by Fourier transform infrared spectroscopy (FTIR, Iraffinity-1, Shimadzu, Japan) in the wavenumber range of $4000-400 \mathrm{~cm}^{-1}$. The morphology was examined by scanning electron microscopy (SEM, Jeol, JSM-6700F). The porous framework and the nanoparticle size were characterized by transmission electron microscopy (Philips, Tecnan F20 operated at $20 \mathrm{kV}$ ).

$\mathrm{N}_{2}$ adsorption isotherms were recorded with a TriStar 3000 apparatus (Quantachrome). The pore size distribution of the aerogels was obtained from the desorption branch of $\mathrm{N}_{2}$ adsorption isotherms using Berrett-Joyner-Hallenda (BJH) method. The specific surface area was obtained by Brunauer-Emmet-Teller (BET) method.

\section{Results and discussion}

\subsection{Effect of calcination temperature on morphology of $\mathrm{SiO}_{2}$ aerogels}

Figure 1 shows the FTIR spectra of the $\mathrm{SiO}_{2}$ aerogels calcined at different temperatures. The asymmetric, symmetric, and rocking bending vibrations of $\mathrm{Si}-\mathrm{O}-\mathrm{Si}$ bonds are observed at 1100,800 , and $468 \mathrm{~cm}^{-1}$, respectively $[19,20]$. The peak at $975 \mathrm{~cm}^{-1}$ is assigned 


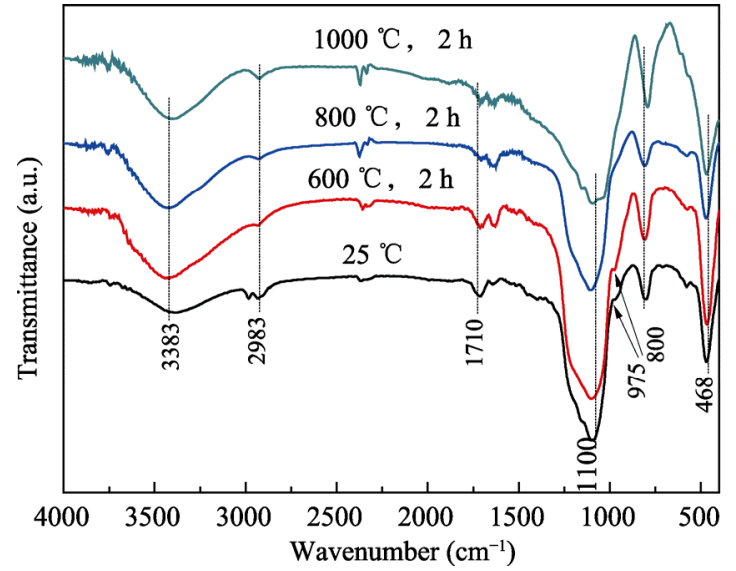

Fig. 1 FTIR spectra of $\mathrm{SiO}_{2}$ aerogels treated at different temperatures.

to a small amount of $\mathrm{Si}-\mathrm{OH}$ groups. The peak at $2983 \mathrm{~cm}^{-1}$ is assigned to vibrations of the $\mathrm{CH}_{3}$ groups, suggesting the presence of $\mathrm{Si}-\mathrm{OC}_{2} \mathrm{H}_{5}$ groups. The presence of these groups suggests an incomplete condensation during gelation process $[19,21,22]$. As the calcination temperature increases, the peak at $975 \mathrm{~cm}^{-1}$ slowly disappears and the intensity of the peak at $2983 \mathrm{~cm}^{-1}$ also decreases, while that of the peak at $800 \mathrm{~cm}^{-1}$ increases. This suggests the formation of additional $\mathrm{Si}-\mathrm{O}-\mathrm{Si}$ bonds by the condensation reaction between $\mathrm{Si}-\mathrm{OH}$ and $\mathrm{Si}-\mathrm{OC}_{2} \mathrm{H}_{5}$. The peak at $1710 \mathrm{~cm}^{-1}$ belongs to vibrations of water molecules [19]. Its intensity deceases with calcination temperature due to removal of water from the framework structure. Figure 2 shows a schematic view of the formation of additional $\mathrm{Si}-\mathrm{O}-\mathrm{Si}$ bonds after the thermal treatment. This process determines the morphological properties of aerogels.

Figure 3 shows O 1s XPS spectra of the as-synthesized aerogel (sample A) and three samples calcined for $2 \mathrm{~h}$ at 400,600 , and $800{ }^{\circ} \mathrm{C}$ (samples B, C, and D, respectively). The binding energy (BE) and the fraction $(\mathrm{mol} \%)$ of different elements are listed in Table 1. This estimation was obtained from the deconvolution of the corresponding XPS bands following the method described in Refs. [23,24]. The peak at 533.18$533.50 \mathrm{eV}$ originates from the $\mathrm{Si}-\mathrm{O}-\mathrm{Si}$ groups $[25,26]$, the peak at $532.62-532.93 \mathrm{eV}$ originates from the $\mathrm{Si}-\mathrm{OH}$ groups [27], while the peak at 532.31$532.46 \mathrm{eV}$ originates from the $\mathrm{Si}-\mathrm{OC}_{2} \mathrm{H}_{5}$ groups [28]. As the calcination temperature increases, the amount of $\mathrm{Si}-\mathrm{O}-\mathrm{Si}$ groups increases from $51.8 \%$ to $96.6 \%$, while that of $\mathrm{Si}-\mathrm{OH}$ and $\mathrm{Si}-\mathrm{OC}_{2} \mathrm{H}_{5}$ groups decreases, indicating the formation of additional bonds of $\mathrm{Si}-\mathrm{O}-\mathrm{Si}$ via the condensation reaction, in agreement with the results obtained from the FTIR study. The formation of the additional bonds of $\mathrm{Si}-\mathrm{O}-\mathrm{Si}$ results in the shrinkage of the aerogel framework structure. This process is responsible for an increase of the total pore volume and the specific surface area. The $\mathrm{Si}-\mathrm{OH}$ groups disappear at $800{ }^{\circ} \mathrm{C}$ while the amount of $\mathrm{Si}-\mathrm{OC}_{2} \mathrm{H}_{5}$ groups decreases to $3.1 \%$, suggesting that the framework is preferentially formed by the $\mathrm{Si}-\mathrm{O}-\mathrm{Si}$ bonds.

Figure 4 shows the XRD patterns of four $\mathrm{SiO}_{2}$ aerogels calcined at different temperatures. Wide peaks are observed in all samples indicating an amorphous structure. The intensity of the main peak increases with the calcination temperature which confirms ongoing crystallization process.

Table 2 shows the specific surface area, pore volume, and pore size of the as-synthesized aerogels and those thermally treated. Additionally, curves of specific surface area and average pore diameter of the $\mathrm{SiO}_{2}$ aerogels obtained from different conditions are shown in Fig. 5.

It can be seen in Table 2 that the surface area of

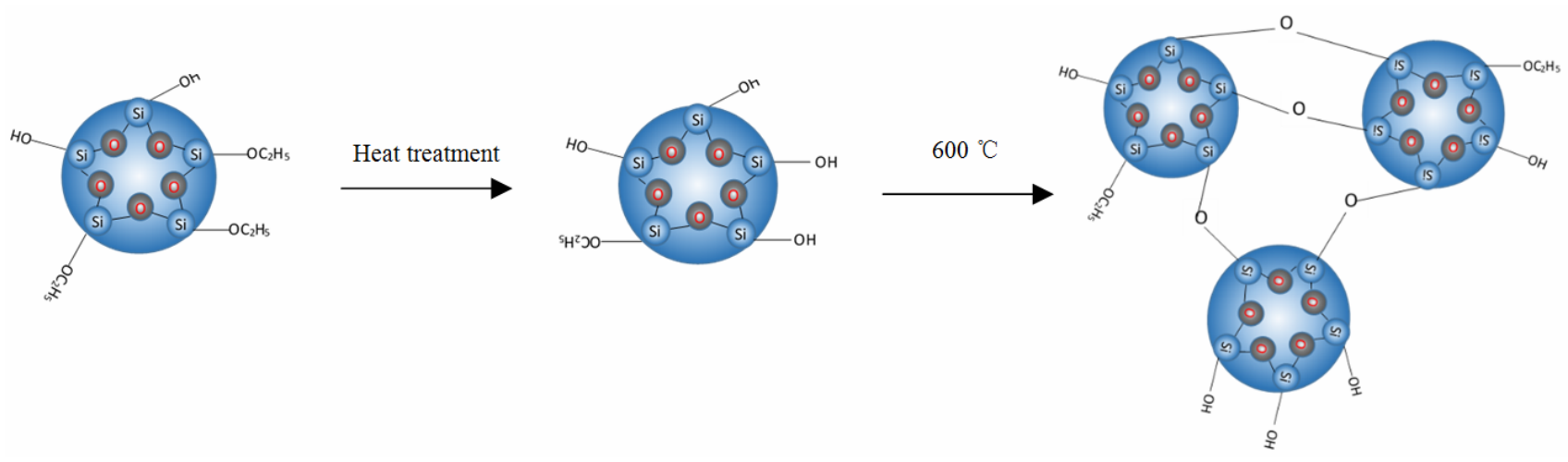

Fig. 2 Schematic view of the formation of additional Si-O-Si bonds in aerogels after a thermal treatment. 
$\mathrm{SiO}_{2}$ aerogels increases initially and then decreases with increasing calcination temperature. It reaches a maximum value of $883 \mathrm{~m}^{2} / \mathrm{g}$ at $600{ }^{\circ} \mathrm{C}$. The pore diameter monotonously decreases due to the formation of additional bonds of $\mathrm{Si}-\mathrm{O}-\mathrm{Si}$ formed via condensation reaction between the silanol group and the remaining $\mathrm{Si}-\mathrm{OC}_{2} \mathrm{H}_{5}$ on the secondary particles [29], as it is also confirmed by the FTIR and XPS studies. Additional pores are formed between the aerogel clusters. The

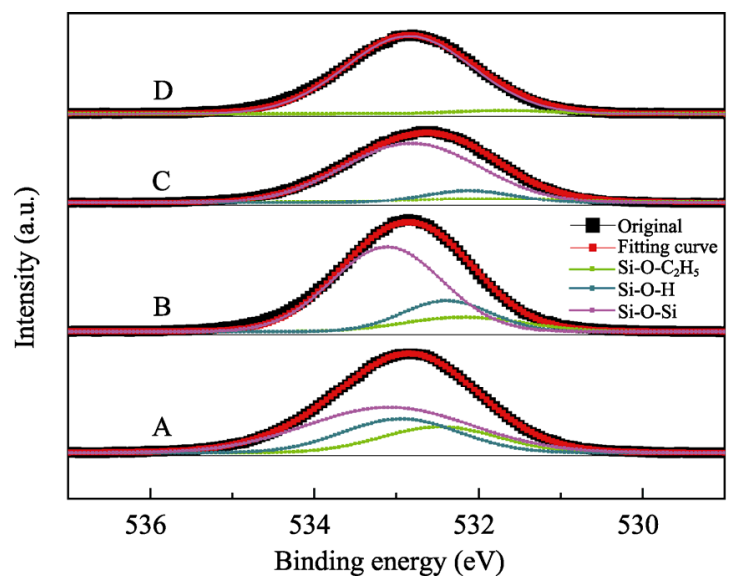

Fig. 3 O 1s XPS spectra of aerogels treated at different temperatures: (A) as-synthesized; (B) $400{ }^{\circ} \mathrm{C}, 2 \mathrm{~h}$; (C) $600{ }^{\circ} \mathrm{C}, 2 \mathrm{~h}$; (D) $800{ }^{\circ} \mathrm{C}, 2 \mathrm{~h}$.

Table 1 Quantitative $\mathrm{O}$ 1s XPS analysis of $\mathrm{SiO}_{2}$ aerogels calcined at different temperatures

\begin{tabular}{lcccc}
\hline & Sample & \multicolumn{4}{c}{ Binding energy $(\mathrm{eV}) /$ atomic percentage (\%) } \\
\cline { 2 - 5 } Orbital & $\mathrm{A}$ & $\mathrm{B}$ & $\mathrm{C}$ & $\mathrm{D}$ \\
\hline $\mathrm{Si}-\mathrm{O}-\mathrm{Si}$ & $533.18 / 51.82$ & $533.31 / 67.25$ & $533.31 / 80.67$ & $533.50 / 96.85$ \\
$\mathrm{Si}-\mathrm{OH}$ & $532.93 / 27.29$ & $532.58 / 19.89$ & $532.62 / 11.21$ & - \\
$\mathrm{Si}-\mathrm{OC}_{2} \mathrm{H}_{5}$ & $532.46 / 20.89$ & $532.37 / 12.55$ & $532.31 / 8.12$ & $532.32 / 3.14$ \\
\hline
\end{tabular}

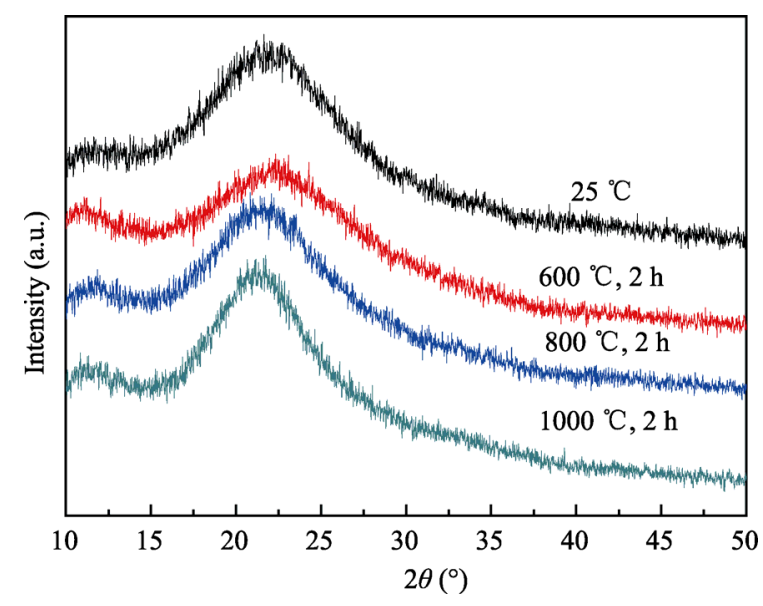

Fig. 4 XRD patterns of $\mathrm{SiO}_{2}$ aerogels calcined at different temperatures. framework structure shrinks due to the formation of the new bonds. This process is responsible for the increase of the specific surface area and it reduces the average pore diameter. The largest particle size increases and the shrinkage of the framework occurs at the highest calcination temperature. This reduces both

Table 2 BET, pore volume, and pore size values of $\mathrm{SiO}_{2}$ aerogels before and after thermal treatment at different temperatures

\begin{tabular}{cccc}
\hline Heat treatment & $\begin{array}{c}\text { Surface } \\
\text { area }\left(\mathrm{m}^{2} / \mathrm{g}\right)\end{array}$ & $\begin{array}{c}\text { Average pore } \\
\text { diameter }(\mathrm{nm})\end{array}$ & $\begin{array}{c}\text { Pore volume } \\
\left(\mathrm{cm}^{3} / \mathrm{g}\right)\end{array}$ \\
\hline Room temperature & 635 & 22.2 & 4.53 \\
$600{ }^{\circ} \mathrm{C}, 2 \mathrm{~h}$ & 883 & 14.7 & 3.45 \\
$600{ }^{\circ} \mathrm{C}, 4 \mathrm{~h}$ & 638 & 6.7 & 2.04 \\
$600{ }^{\circ} \mathrm{C}, 8 \mathrm{~h}$ & 600 & 11.5 & 2.28 \\
$800{ }^{\circ} \mathrm{C}, 2 \mathrm{~h}$ & 727 & 7.9 & 1.64 \\
$800{ }^{\circ} \mathrm{C}, 4 \mathrm{~h}$ & 299 & 17.6 & 1.23 \\
$800{ }^{\circ} \mathrm{C}, 8 \mathrm{~h}$ & 224 & 11.6 & 1.01 \\
$1000{ }^{\circ} \mathrm{C}, 2 \mathrm{~h}$ & 2.06 & 3.1 & 0.005 \\
$1000{ }^{\circ} \mathrm{C}, 4 \mathrm{~h}$ & 0.61 & 1.4 & 0.07 \\
$1000{ }^{\circ} \mathrm{C}, 8 \mathrm{~h}$ & 2.07 & 0.3 & 0.01 \\
\hline
\end{tabular}
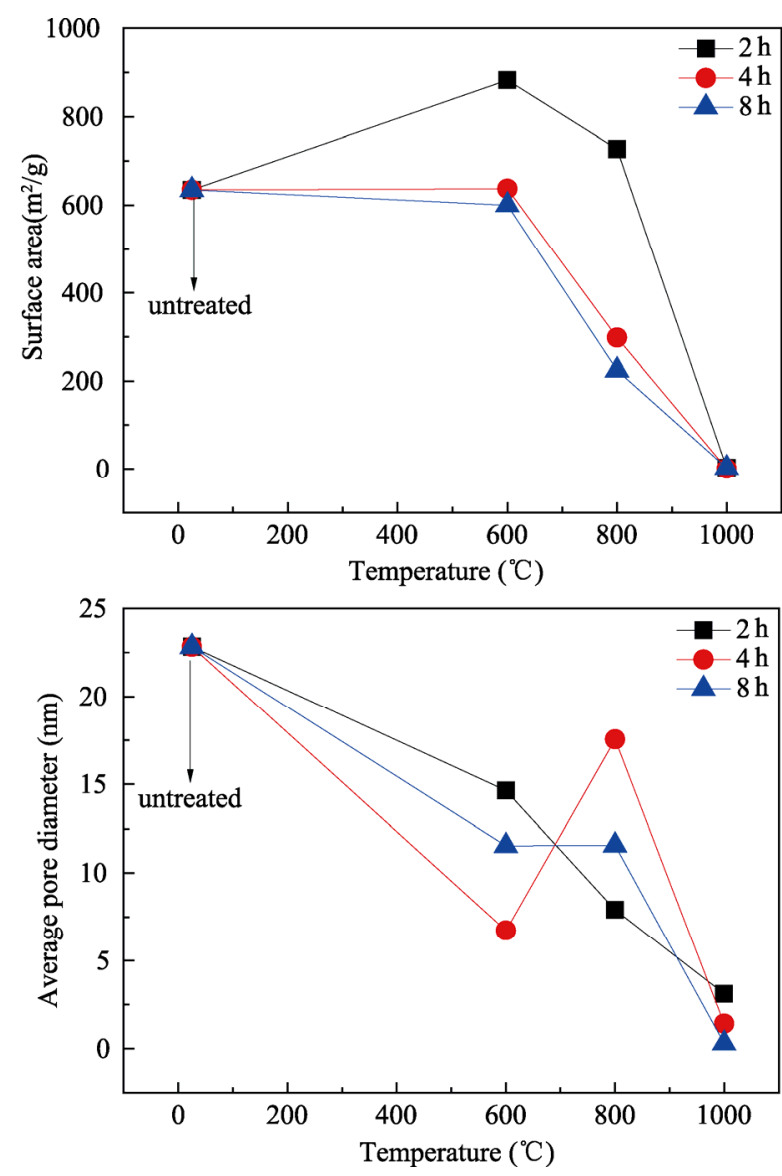

Fig. 5 Specific surface area and average pore diameter of $\mathrm{SiO}_{2}$ aerogels treated at different temperatures. 
the surface area and the average pore diameter. The surface area of aerogels decreases dramatically after a long exposure to high temperature due to the continuous framework shrinkage of the $\mathrm{SiO}_{2}$ aerogels.

Figure 6 shows typical $\mathrm{N}_{2}$ adsorption/desorption isotherms and the corresponding pore size distribution (PSD) plots of the aerogels before and after thermal treatment. The PSD plots were obtained from the desorption branch of $\mathrm{N}_{2}$ isotherms by the $\mathrm{BJH}$ method. The presence of hysteresis loop is due to the capillary condensation occurred in the mesoporous [31]. The nitrogen adsorption follows type-IV isotherm indicating that a rather high amount of mesopores is present in the structure of $\mathrm{SiO}_{2}$ aerogel [30]. The number of mesoporous decreases at higher temperatures due to the accumulation of larger secondary particles. The average mesopore size of the as-synthesized aerogels is in the range of $20-40 \mathrm{~nm}$. The $\mathrm{SiO}_{2}$ aerogel treated at $600{ }^{\circ} \mathrm{C}$ for $2 \mathrm{~h}$ has a broader PSD with an average diameter of $14.7 \mathrm{~nm}$. After the thermal treatment for
$4 \mathrm{~h}$, the mean pore size shifts to a lower value $(6.7 \mathrm{~nm})$. The PSD becomes more uniform, which can be caused by a complete transformation of the remaining $\mathrm{Si}-\mathrm{OC}_{2} \mathrm{H}_{5}$ groups to $\mathrm{Si}-\mathrm{OH}$ groups by oxidation [32]. However, the samples calcined for $8 \mathrm{~h}$ have a wider PSD than those calcined for 4 and $2 \mathrm{~h}$. The latter could be due to the fact that the framework shrinks and the particles grow even after a time period of $4 \mathrm{~h}$. This plays an important role in the stabilization of the porous framework. A surface area of $727 \mathrm{~m}^{2} / \mathrm{g}$ and an average pore diameter of $7.9 \mathrm{~nm}$ were observed after the treatment at $800{ }^{\circ} \mathrm{C}$ for $2 \mathrm{~h}$, The number of pores reduces and the pore size distribution becomes non-uniform. Moreover, the surface area reduces dramatically after the treatments with a duration of more than $4 \mathrm{~h}$. This reveals that the particles keep growing and the framework finally collapses. A further increase in the temperature to $1000{ }^{\circ} \mathrm{C}$ results in a complete collapse of porous structure. The samples transform to a semitransparent glass with little porosity [33].
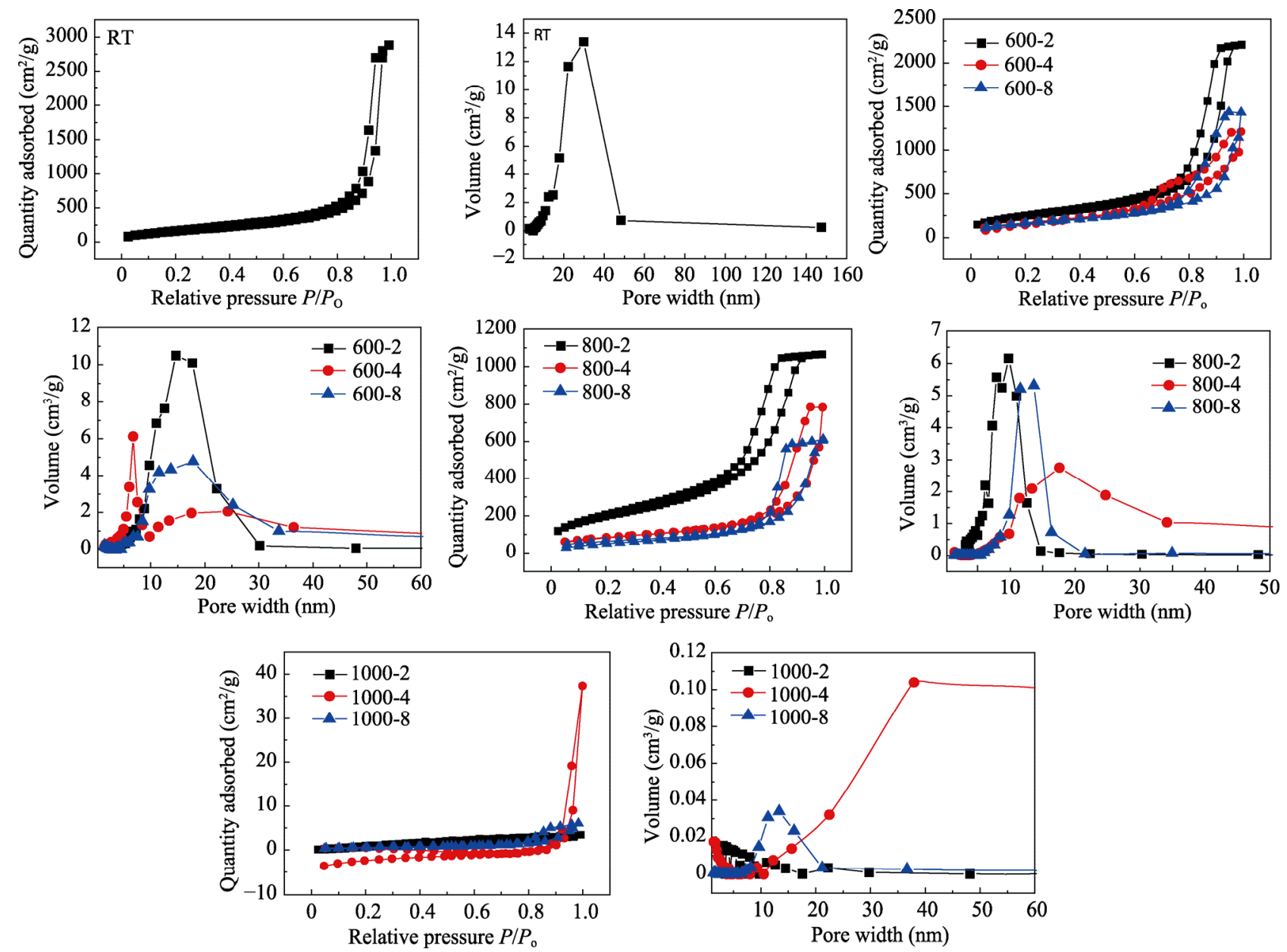

Fig. $6 \mathrm{~N}_{2}$ adsorption/desorption isotherms and the PSD of $\mathrm{SiO}_{2}$ aerogels before and after thermal treatment. 


\section{2 Morphology and microstructure of $\mathrm{SiO}_{2}$ aerogels}

Figure 7 presents typical SEM photographs of $\mathrm{SiO}_{2}$ aerogels before and after the thermal treatment. It can be seen that the secondary particles are aggregated and condensed to form clusters. The crosslinking among these clusters generates a porous framework. As the temperature increases, the amount of mesopores first increases (in Fig. 7(b)) and then decreases (in Figs. 7(c) and $7(d)$ ). The morphology of the porous framework in aerogels changes from loose (in Fig. 7(a)) to compact (in Fig. 7(b)), and then dense (in Fig. 7(c)). Finally the formation of larger particles results in a collapse of porous structure (in Fig. 7(d)). It can also be seen that the pore shape changes from a tetrahedron to an octahedron.

Figure 8 shows TEM images of the $\mathrm{SiO}_{2}$ aerogels calcined at different temperatures. All samples show a randomly interconnected framework, which is composed of irregular spherical nanoparticles. As it can be seen in Figs. 8(a), 8(b), and 8(c), the particle size of these samples ranges between 5 and $10 \mathrm{~nm}$, while much bigger particles of $40-50 \mathrm{~nm}$ are observed at $1000{ }^{\circ} \mathrm{C}$ (Fig. 8(d)). This indicates that the neck growth results in the collapse of the tunnel structure above $800{ }^{\circ} \mathrm{C}$.

\section{3 Nanoporous framework evolution of $\mathrm{SiO}_{2}$ aerogels calcined at different temperatures}

No literature reports on the evolution of mesoporous framework of the aerogels during the calcination process. However, the understanding of this process is important for prediction of the morphology and the thermal stability of the aerogels. According to the electrostatic valence rule, the cells of $\mathrm{SiO}_{2}$ aerogel possess $\left[\mathrm{SiO}_{4}\right]$ tetrahedron structure, and vertexes of this structure are occupied by the same structure. Being connected together, they form a three-dimensional network structure, a spherical granular-secondary particle [34]. These secondary particles connect with each other to form the polyhedron-nanoporous framework.

Thus, we assume that the microstructure of the aerogel is composed of different regular polyhedrons, and the pore size is controlled by the diameter of face inscribed circle. In turn, the pore volume equals to the
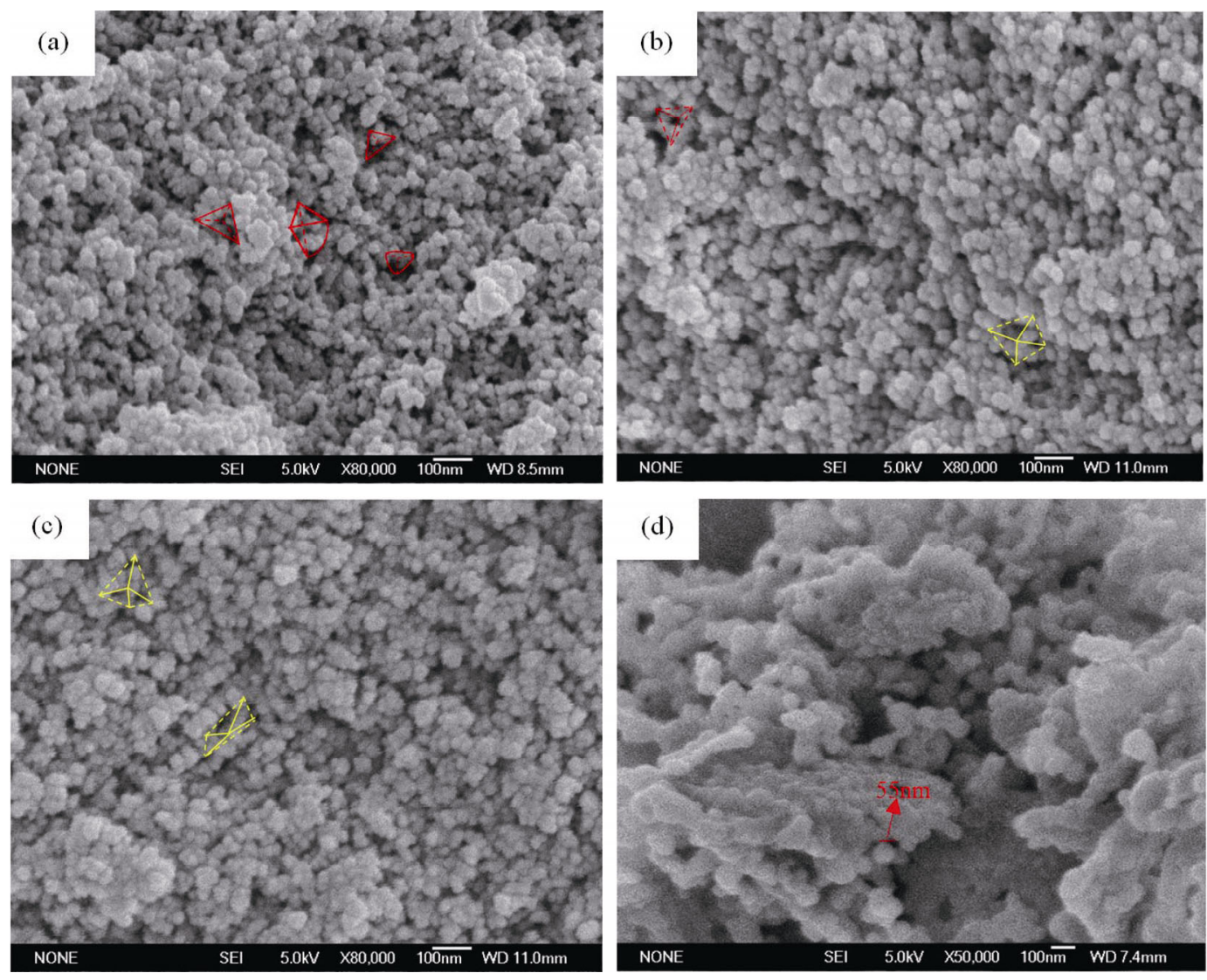

Fig. 7 SEM images of $\mathrm{SiO}_{2}$ aerogels calcined at different temperatures: (a) room temperature; (b) $600{ }^{\circ} \mathrm{C}, 2 \mathrm{~h}$; (c) $800{ }^{\circ} \mathrm{C}, 2 \mathrm{~h}$; (d) $1000{ }^{\circ} \mathrm{C}, 2 \mathrm{~h}$. Graphics in red stand for tetrahedron, yellow for octahedron. 

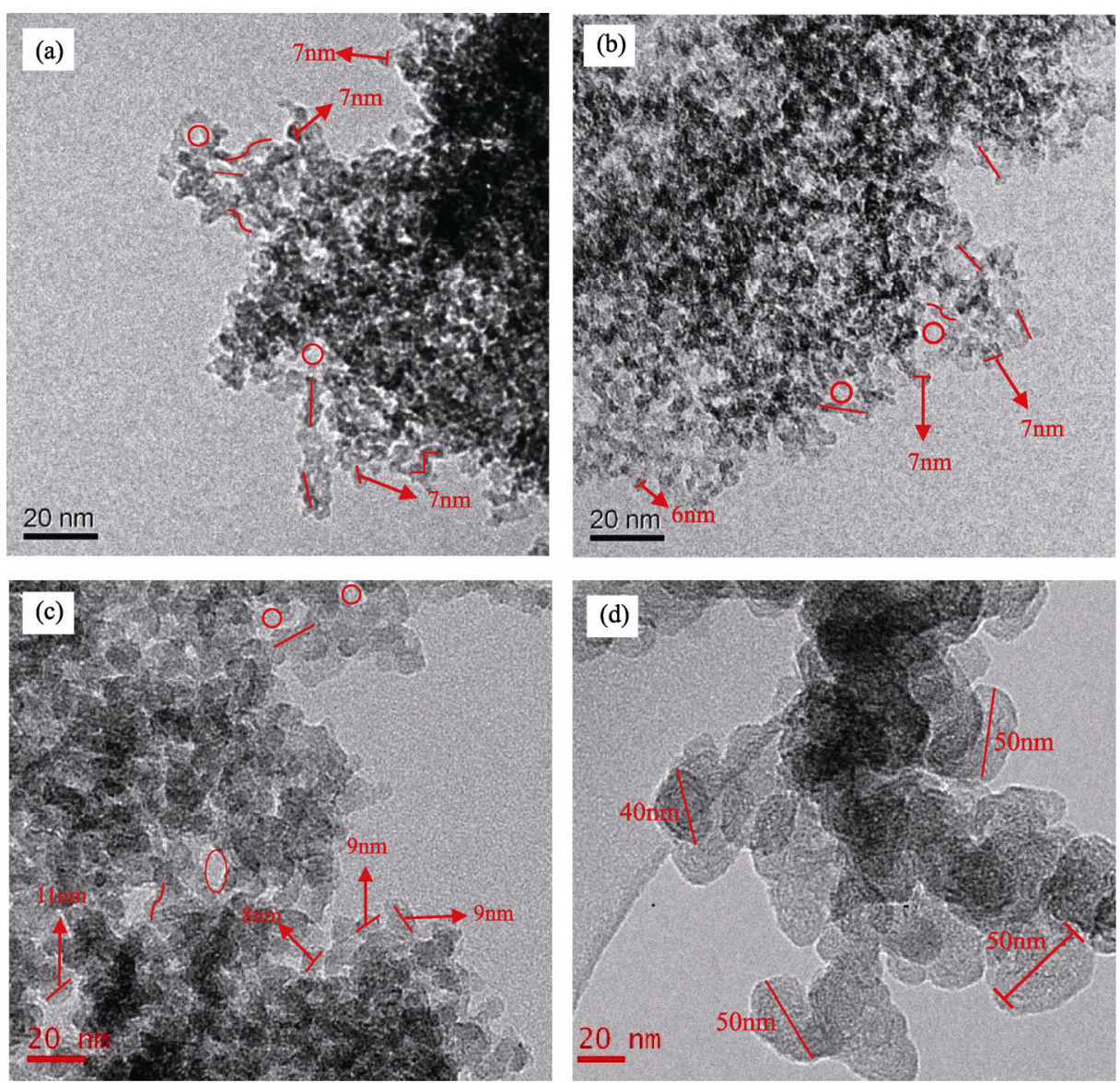

Fig. 8 TEM images of $\mathrm{SiO}_{2}$ aerogels calcined at different temperatures: (a) room temperature; (b) $600{ }^{\circ} \mathrm{C}, 2 \mathrm{~h}$; (c) $800{ }^{\circ} \mathrm{C}, 2 \mathrm{~h}$; (d) $1000{ }^{\circ} \mathrm{C}, 2 \mathrm{~h}$; symbols of circle stand for pores and line for framework.

sum of individual polyhedron volumes. The following equations are used to estimate the key parameters of the mesoporous framework evolution.

Firstly, the weight of each secondary particle is calculated by Eq. (1):

$$
m=\frac{4}{3} \pi \times\left(\frac{d}{2}\right)^{3} \times \rho_{\text {aerogel }}
$$

The number of secondary particles is calculated by Eq. (2):

$$
N=\frac{M}{m}=\frac{6 M}{\pi d^{3} \rho_{\text {aerogel }}}
$$

where $m$ is the weight of secondary particles, $d$ is its diameter (nm) (taken from TEM images), $M$ is the sample weigth, and $\rho_{\text {aerogel }}$ is the apparent density of the silica aerogel $\left(2.1 \mathrm{~g} / \mathrm{cm}^{3}\right)$ [35].

The number of particles on each edge of polyhedron (remove both ends) is calculated by Eq. (3):

$$
m=\frac{a-d}{d}
$$

The total number of particles of each regular polyhedron is calculated by Eq. (4):

$$
p=e \times \beta+m \times h \times \frac{\theta}{2 \pi}
$$

The number of regular polyhedron is calculated by Eq. (5):

$$
n=\frac{N}{p}
$$

Combining Eqs. (1), (2), (3), (4), and (5), the total volume of polyhedrons in the aerogel can be calculated by Eq. (6):

$$
V=\frac{12 M}{d^{2} \rho_{\text {aerogel }}[2 e \pi d \beta+h \theta(a-d)]} \times V_{\text {regular-polyhedron }}
$$

where $a$ represents the polyhedron edge length, $\beta$ is the space volume percentage occupied by vertex, $h$ is the number of edge of regular polyhedron, $e$ is the vertex number, and $\theta$ is the dihedral angle. The estimated framework and calculated pore volume of $\mathrm{SiO}_{2}$ aerogels are listed in Table 3. The calculated results are 
Table 3 Estimated porous framework and calculated pore volume of $\mathrm{SiO}_{2}$ aerogels treated at different temperatures

\begin{tabular}{|c|c|c|c|c|c|c|c|}
\hline Heat treated conditions & Room temperature & \multicolumn{2}{|c|}{$600{ }^{\circ} \mathrm{C}, 2 \mathrm{~h}$} & \multicolumn{2}{|c|}{$700{ }^{\circ} \mathrm{C}, 2 \mathrm{~h}$} & $800{ }^{\circ} \mathrm{C}, 2 \mathrm{~h}$ & $1000{ }^{\circ} \mathrm{C}, 2 \mathrm{~h}$ \\
\hline Desorption pore volume $\left(\mathrm{cm}^{3}\right)$ & 0.2065 & \multicolumn{2}{|c|}{0.2021} & \multicolumn{2}{|c|}{0.1016} & 0.0531 & 0.0052 \\
\hline Regular polyhedron type & Tetrahedron & Tetrahedron & Octahedron & Tetrahedron & Octahedron & Octahedron & - \\
\hline Total polyhedral volume $\left(\mathrm{cm}^{3}\right)$ & 0.2402 & 0.1704 & 0.2282 & 0.0815 & 0.1101 & 0.0545 & $2.3 \times 10^{-3}$ \\
\hline Estimated nanoporous framework & Total tetrahedron & \multicolumn{2}{|c|}{ Tetrahedron:octahedron $=1: 1$} & \multicolumn{2}{|c|}{ Tetrahedron:octahedron $=1: 2$} & Total octahedron & Densification \\
\hline Calculated pore volume $\left(\mathrm{cm}^{3}\right)$ & 0.2402 & \multicolumn{2}{|c|}{0.1993} & \multicolumn{2}{|c|}{0.1005} & 0.0545 & - \\
\hline
\end{tabular}

compared with the corresponding experimental data.

It can be seen in Table 3 that the calculated values of pore volume are in good agreement with the experimental results. The porous framework of as-synthesized samples consists of tetrahedrons and that calcined at $1000{ }^{\circ} \mathrm{C}$ of octahedrons. A tetrahedron to octahedron ratio of 1 is observed in samples calcined at $600{ }^{\circ} \mathrm{C}$, while this ratio decreases to 0.5 after calcination at $800{ }^{\circ} \mathrm{C}$.

Figure 9 presents a schematic evolution of $\mathrm{SiO}_{2}$ aerogel framework as a function of calcination temperature. Figure 10 shows further geometrical interpretation of the model proposed. As for $\mathrm{SiO}_{2}$ aerogels at room temperature in Fig. 9, the nanoporous framework totally is composed of tetrahedron with a pore size of about $22.28 \mathrm{~nm}$; as the temperature reaches to $600{ }^{\circ} \mathrm{C}$, the framework is composed of tetrahedron and octahedron with a ratio of 1:1. It becomes more compact, being due to the formation of extra $\mathrm{Si}-\mathrm{O}-\mathrm{Si}$ bond via the condensation reaction between $\mathrm{Si}-\mathrm{OH}$ and/or $\mathrm{Si}-\mathrm{OC}_{2} \mathrm{H}_{5}$ on the secondary particles, as shown in Fig. 2, and it is also consistent with the SEM (Fig. 6(b)). When the temperature reaches to $700{ }^{\circ} \mathrm{C}$, the quantity ratio of tetrahedron and octahedron reaches up to $1: 2$. The pore size of aerogel is $11.04 \mathrm{~nm}$ at $700{ }^{\circ} \mathrm{C}$. With the heat treatment temperature increases to $800{ }^{\circ} \mathrm{C}$, the nanoporous framework totally is composed of octahedron with a pore size of about $7.91 \mathrm{~nm}$. In addition, the newly formed $\mathrm{Si}-\mathrm{O}-\mathrm{Si}$ bonds can produce a shrinkage of nanoporous framework and result in a decrease of pore size. A high local stress and the liquid in the pores between the particles result in the deformation of individual particles. This process can eventually cause a rearrangement of particles during the thermal treatment process [36]. Above $600{ }^{\circ} \mathrm{C}$, the newly formed $\mathrm{Si}-\mathrm{O}-\mathrm{Si}$ bonds and the rearrangement of particles result in a variety of pore shapes and particles sizes. The aerogels are stabilized by reducing the surface energy via the pore collapse and particle growth after the treatment at $1000{ }^{\circ} \mathrm{C}$, as shown in Fig. 7(d).
In reality, the geometric figure shown in Fig. 9 should be a twisted shape as the silica aerogels mainly consist of $\mathrm{Si}-\mathrm{O}-\mathrm{Si}$ groups whose bond angle is $109^{\circ} 28^{\prime}$. Due to the calculation requirement, the model was described by tetrahedron and octahedron.

\section{Conclusions}

(1) $\mathrm{SiO}_{2}$ aerogels treated at different temperatures and holding time all possess amorphous structure; with the increase of treated temperatures, it has an obvious trend of crystallization.

(2) With the increase of treated temperatures, BET values of $\mathrm{SiO}_{2}$ aerogels increase initially and then decrease; it reaches maximum value of $882.81 \mathrm{~m}^{2} / \mathrm{g}$ when treated at $600{ }^{\circ} \mathrm{C}$ for $2 \mathrm{~h}$, while the values of average pore diameter simply decrease. These varieties may be due to the newly formed $\mathrm{Si}-\mathrm{O}-\mathrm{Si}$ bonds via condensation reaction between the secondary particles during heat treatment process; it can not only add the amount of nanopores but also help to shrink the skeleton; the former can improve the BET values and the latter helps to reduce the average pore diameter of aerogels. A higher temperature may result in the skeleton transformation and particle size growth; both factors lead to the reduction of BET and average pore diameter values.

(3) Nanoporous skeleton of $\mathrm{SiO}_{2}$ aerogels at room temperatures is mainly composed of tetrahedron with a pore size of about $22.28 \mathrm{~nm}$, and when treated at $600{ }^{\circ} \mathrm{C}$, its microstructure is mainly composed of tetrahedron and octahedron with a ratio of 1:1 and the relative pore size is about $14.65 \mathrm{~nm}$. A higher temperature results in an increase of octahedron amount in the nanoporous framework and a decrease of the pore size in aerogels. Finally, treating at $1000{ }^{\circ} \mathrm{C}$ results in an approximate dense $\mathrm{SiO}_{2}$ bulk via the framework collapse and particle growth. The newly formed $\mathrm{Si}-\mathrm{O}-\mathrm{Si}$ bonds, the high local stress, and liquid 


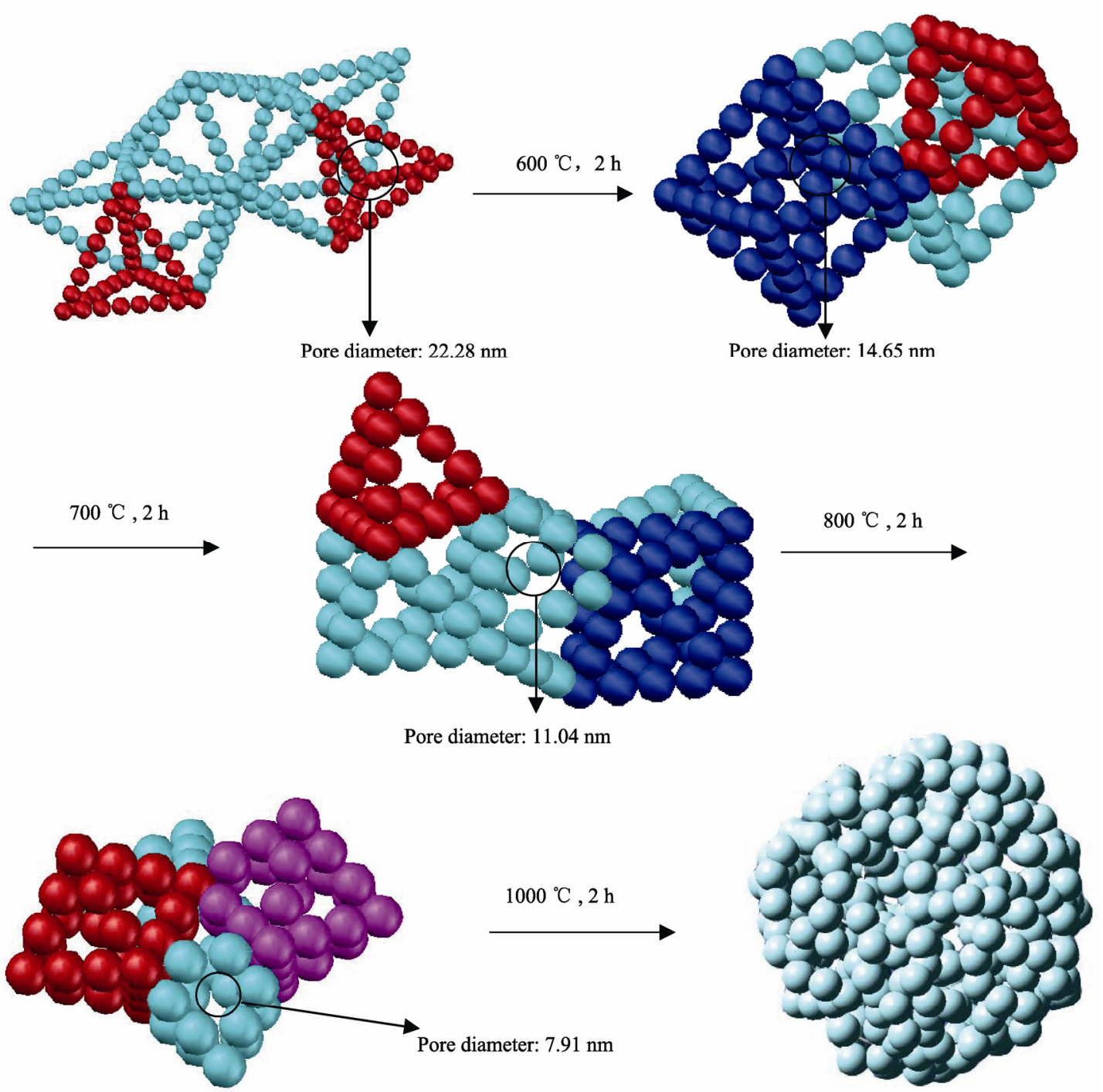

Fig. 9 Models of the transformation mechanism of pore structure during heat treatment.

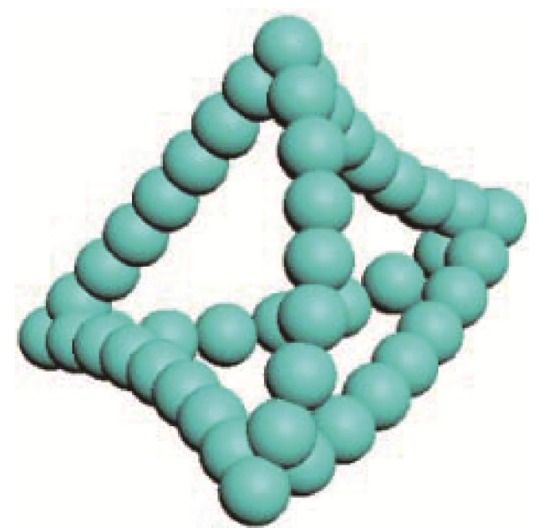

Fig. 10 Additional interpretation of geometric model.

phase between particles can cause the particle growth and rearrangement of nanoporous framework.

\section{References}

[1] Gao QF. Nano-porous silica, alumina aerogels and thermal super-insulation composites. Ph.D. Thesis. Changsha, China: National University of Defense Technology, 2009. (in Chinese)

[2] Rueda M, Sanz-Moral LM, Nieto-Márquez A, et al. Production of silica aerogel microparticles loaded with ammonia borane by batch and semicontinuous supercritical drying techniques. $J$ Supercrit Fluid 2014, 92: 299-310.

[3] Lu G, Wang X-D, Duan Y-Y, et al. Effects of non-ideal structures and high temperatures on the insulation properties of aerogel-based composite materials. $J$ NonCryst Solids 2011, 357: 3822-3839.

[4] Li M, Jiang H, Xu D, et al. Low density and hydrophobic silica aerogels dried under ambient pressure using a new co-precursor method. J Non-Cryst Solids 2016, 452: 
187-193.

[5] Tang X, Sun A, Chu C, et al. A novel silica nanowire-silica composite aerogels dried at ambient pressure. Mater Design 2017, 115: 415-421.

[6] Li XW, Duan YY, Wang XD. Impacts of structural changes of $\mathrm{SiO}_{2}$ aerogel under high temperature on its insulation performance. J Therm Sci Tech 2011, 10: 189-193.

[7] Maleki H, Durães L, Portugal A. A new trend for development of mechanical robust hybrid silica aerogels. Mater Lett 2016, 179: 206-209.

[8] Lu Z, Yuan Z, Liu Q, et al. Multi-scale simulation of the tensile properties of fiber-reinforced silica aerogel composites. Mat Sci Eng A 2015, 625: 278-287.

[9] Kim C-Y, Lee J-K, Kim B-I. Synthesis and pore analysis of aerogel-glass fiber composites by ambient drying method. Colloid Surf A 2008, 313-314: 179-182.

[10] Wu H, Liao Y, Ding Y, et al. Engineering thermal and mechanical properties of multilayer aligned fiber-reinforced aerogel composites. Heat Transfer Eng 2014, 35: 10611070.

[11] Fenech J, Viazzi C, Bonino J-P, et al. Morphology and structure of YSZ powders: Comparison between xerogel and aerogel. Ceram Int 2009, 35: 3427-3433.

[12] Reichenauer G, Heinemann U, Ebert H-P. Relationship between pore size and the gas pressure dependence of the gaseous thermal conductivity. Colloid Surf A 2007, 300: 204-210.

[13] Zhou CL, Yang J, Sui XY, et al. Impacts of structural change of $\mathrm{SiO}_{2}$ aerogel under different time and high temperature conditions on insulation performance. $A d v$ Ceram 2014, 5: 11-16.

[14] Huang D, Guo C, Zhang M, et al. Characteristics of nanoporous silica aerogel under high temperature from $950{ }^{\circ} \mathrm{C}$ to $1200{ }^{\circ} \mathrm{C}$. Mater Design 2017, 129: 82-90.

[15] Olivi-Tran N, Jullien R. Numerical simulations of aerogel sintering. Phys Rev B 1995, 52: 258.

[16] Chu P, Liu H, Li Y, et al. Syntheses of $\mathrm{SiC}-\mathrm{TiO}_{2}$ hybird aerogel via supercritical drying combined PDCs route. Ceram Int 2016, 42: 17053-17058.

[17] Rao AV, Hegde ND, Hirashima H. Absorption and desorption of organic liquids in elastic superhydrophobic silica aerogels. J Colloid Interface Sci 2007, 305: 124-132.

[18] Zhang Z, Scherer GW. Supercritical drying of cementitious materials. Cement Concrete Res 2017, 99: 137-154.

[19] Shao Z, Luo F, Cheng X, et al. Superhydrophobic sodium silicate based silica aerogel prepared by ambient pressure drying. Mater Chem Phys 2013, 141: 570-575.

[20] Saeed S, Soubaihi RMA, White LS, et al. Rapid fabrication of cross-linked silica aerogel by laser induced gelation. Microporous Mesoporous Mater 2016, 221: 245-252.

[21] García-Torres BA, Aguilar-Elguezabal A, Román-Aguirre $\mathrm{M}$, et al. Synthesis of silica aerogels microspheres prepared by ink jet printing and dried at ambient pressure without surface hydrophobization. Mater Chem Phys 2016, 172: $32-38$.
[22] Shahzamain M, Bagheri R, Masoomi M. Synthesis of silica-polybutadiene hybrid aerogel: The effects of reaction conditions on physical and mechanical properties. $J$ Non-Cryst Solids 2016, 452: 325-335.

[23] Sutka A, Pärna R, Mezinskis G, et al. Effects of Co ion addition and annealing conditions on nickel ferrite gas response. Sensor Actuat B: Chem 2014, 192: 173-180.

[24] Barba A, Clausell C, Nuño L, et al. $\mathrm{ZnO}$ and $\mathrm{CuO}$ crystal precipitation in sintering $\mathrm{Cu}$-doped $\mathrm{Ni}-\mathrm{Zn}$ ferrites. II. Influence of sintering temperature and sintering time. J Eur Ceram Soc 2017, 37: 169-177.

[25] Nocun M, Cholewa-Kowalska K, Łączka M. Structure of hybrids based on TEOS-cyclic forms of siloxane system. $J$ Mol Struct 2009, 938: 24-28.

[26] Wang H, Wu Q, Cao D, et al. Synthesis of SnSb-embedded carbon-silica fibers via electrospinning: Effect of TEOS on structural evolutions and electrochemical properties. Mater Today 2016, 1-2: 24-32.

[27] Yang J, Chen J. Surface free energy and surface structure of methyl-modified silica membranes. J Mater Eng 2008, 10: 177-182.

[28] Kim N-H, Ko P-J, Seo Y-J, et al. Improvement of TEOSchemical mechanical polishing performance by control of slurry temperature. Microelectron Eng 2006, 83: 286-292.

[29] Li Z, Gong L, Li C, et al. Silica aerogel/aramid pulp composites with improved mechanical and thermal properties. J Non-Cryst Solids 2016, 454: 1-7.

[30] He S, Huang D, Bi H, et al. Synthesis and characterization of silica aerogels dried under ambient pressure bed on water glass. J Non-Cryst Solids 2015, 410: 58-64.

[31] Sing KSW, Williams RT. Physisorption hysteresis loops and the characterization of nanoporous materials. Adsorpt Sci Technol 2004, 22: 773-782.

[32] Shi C, Zhang S, Jiang Y, et al. High temperature properties of silica aerogel. Rare Metal Mat Eng 2016, 45: 210-213.

[33] Wagh PB, Pajonk GM, Haranath D, et al. Influence of temperature on the physical properties of citric acid catalyzed TEOS silica aerogels. Mater Chem Phys 1997, 50: 76-81.

[34] Li Z-H, Gong Y-J, Pu M, et al. Determination of structure of $\mathrm{SiO}_{2}$ colloidal particle by SAXS. Chin J Inorg Chem 2003, 19: 252-256.

[35] Morales-Flórez V, Rosa-Fox NDL, Piñero M, et al. The cluster model: A simulation of the aerogel structure as a hierarchically-ordered arrangement of randomly packed spheres. J Sol-Gel Sci Technol 2005, 35: 203-210.

[36] Kuczynski GC. Sintering Processes. Now York, 1979.

Open Access The articles published in this journal are distributed under the terms of the Creative Commons Attribution 4.0 International License (http://creativecommons.org/licenses/ by/4.0/), which permits unrestricted use, distribution, and reproduction in any medium, provided you give appropriate credit to the original author(s) and the source, provide a link to the Creative Commons license, and indicate if changes were made. 